\title{
ERGONOMIC FIELD ASSESSMENT OF BUCKING BARS DURING RIVETING TASKS
}

\author{
Michael J. Jorgensen and Muthukurappan Viswanathan \\ Industrial and Manufacturing Engineering Department \\ Wichita State University \\ Wichita, KS
}

\begin{abstract}
Riveting tasks in aircraft manufacturing results in exposure to vibration from both rivet guns and bucking bars. Long term exposure to vibration has been associated with symptoms of vibration white finger and musculoskeletal disorders. Four different bucking bars of the same shape but different material and mass characteristics $(90 \%$ tungsten, $>90 \%$ tungsten, cold rolled and stainless ste i) were investigated for vibration and grip muscle activity during a riveting task. The $>90 \%$ and $90 \%$ tungsten bars $(3.4$ $\mathrm{m} / \mathrm{s}^{2}$ and $3.6 \mathrm{~m} / \mathrm{s}^{2}$, respectively) resulted in significantly less mean resultant weighted acceleration when compared to the cold rolled and stainless steel $\left(5.3 \mathrm{~m} / \mathrm{s}^{2}\right.$ and $5.6 \mathrm{~m} / \mathrm{s}^{2}$, respectively), whereas there was no difference in mean hand grip flexor or extensor muscle activity. These results suggest that for bucking tasks that allow access for the bucking bar size investigated, use of heavier but same sized tungsten bucking bars can reduce vibration transmission to the hand.
\end{abstract}

\section{INTRODUCTION}

Although the use of composite materials is increasing in the manufacturing of aircraft, manual riveting operations are still very pervasive in the assembly of aircraft. Riveting operations in aircraft manufacturing involves the use of power tools for manually drilling and countersinking holes for the rivets, as well as the use of air hammers or rivet guns to drive and set the rivets. Additionally, to close the rivet, the rivet is driven against a metallic bar commonly called a "bucking bar". The bucking bars are typically held manually, and must be held firmly to increase the quality of the riveting, as well as keep the bucking bar from "dancing" against the metal piece being riveted. Thus, employees in aircraft manufacturing involved in riveting are exposed to hand-arm vibration from several sources.

Vibration exposure in aircraft manufacturing has been historically associated with self reports of health complaints related to vibration-related musculoskeletal disorders. Engstrom and Dandanell (1986) found that more than $50 \%$ of riveters in one aircraft division had symptoms of vibration-induced white finger after more than 10 years of work. Dandanell and
Engstrom (1986) reported that the vibration characteristics for air hammers and bucking bars were in a similar range of 10 to $11 \mathrm{~m} / \mathrm{s}^{2}$, whereas Burdorf and Monster (1991) found frequencyweighted acceleration ranges from 5.5 to $12.3 \mathrm{~m} / \mathrm{s}^{2}$. Burdorf and Monster (1991) also found an association between vibration-induced white finger and pain or stiffness of the wrist after 10 years of exposure to riveting and bucking tasks.

Recently, bucking bars made of tungsten have been utilized for some riveting tasks at a local aircraft manufacturer, where subjective reports from the employees suggested less vibration was transmitted to the hands. However, since the tungsten bars weigh approximately 2.3 times more than the steel bucking bars of the same size and shape, the company was reluctant to implement tungsten bucking bars on a full scale. While the increased mass of the tungsten bar may be an advantage as far as dampening the vibration, the effect on the hand grip exertion levels was unknown. Therefore, the overall objective of this study was to perform a field evaluation to quantify and compare the vibration transmission and grip muscle activity characteristics when using bucking 
bars of the same size and shape, but made of different materials.

\section{METHODS}

\section{Approach}

This investigation measured and compared vibration and impact forces transmitted to the bucking bars of different materials utilizing an accelerometer attached to the bucking bar while employees held the bars. This investigation also quantified and compared the exertion level of the hand grip muscles using electromyography (EMG) while using bucking bars of different materials.

\section{Subjects}

Five employees (three females and two males) who were experienced at bucking rivets volunteered to participate in this study. The mean (SD) age and years of experience for the subjects was 45.0 yrs (9.8) and 15.8 yrs (11.7, respectively. Each employee was briefed on the objectives of this study and signed an informed consent form approved by the Wichita State University Internal Review Board for Human Subjects.

\section{Experimental Design}

The independent variable consisted of the bucking bar, for which four bucking bars of different materials were investigated. The dependent variables consisted of mean percent maximum hand grip muscle activity for the flexor and extensor muscle groups, mean and peak resultant weighted acceleration, and the ISO 5349 estimated exposure period until $10 \%$ of a population exposed to four hours a day of the measured vibration levels developed blanching of the fingers.

\section{Equipment}

All four bucking bars were cut to the same size and shape $(6.7 \times 2.4 \times 1.7 \mathrm{~cm} ; \mathrm{L} \times \mathrm{H} \times \mathrm{W})$ (Figure 1). The cold rolled bar weighed $389.6 \mathrm{~g}$, the stainless steel bar weighed $385.5 \mathrm{~g}$, the $90 \%$ tungsten bar weighed $807.2 \mathrm{~g}$, and the $>90 \%$ tungsten bar weighed $902.3 \mathrm{~g}$. One employee using the same air hammer (size E2) drove the rivets for all subjects using the bucking bars. A square skin (approximately 12 inches by 12 inches) was fitted with six vertical rows of rivets, and was attached to a vertical metal frame to provide stability to the skin for the riveting and bucking task (Figure 2).

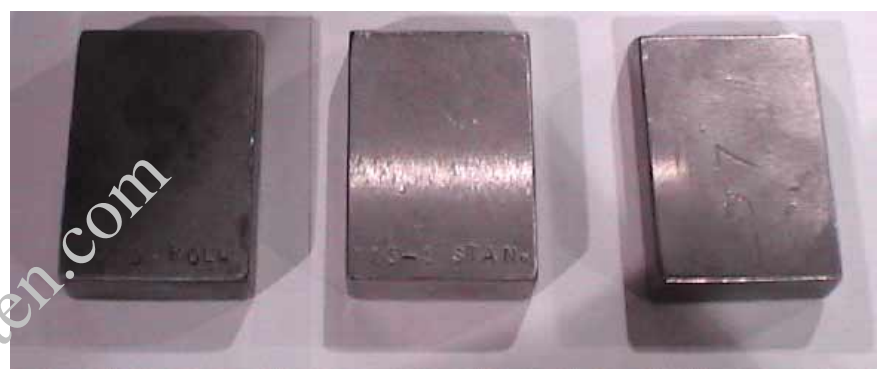

Figure 1. Bucking bars used for experimental tasks. The left bucking bar is made of cold rolled steel, the middle bucking bar is made of stainless steel, and the right bucking bar is made of $>90 \%$ tungsten. The $90 \%$ tungsten (not shown) was the same size as those shown in the figure.

A datalogger (Biometrics DataLOG II) was used to collect the vibration and electromyography data during the experimental trials. Bucking bar vibration was collected using a $10 \mathrm{~g}$ tri-axial accelerometer (Biometrics S2-10G-MF Series 2), and right hand/wrist flexor and extensor muscle activity was collected from a bipolar EMG sensors (Biometrics SX230). The accelerometer voltages were collected at $5000 \mathrm{~Hz}$, whereas the EMG voltages were collected simultaneously at $1000 \mathrm{~Hz}$ by the datalogger.

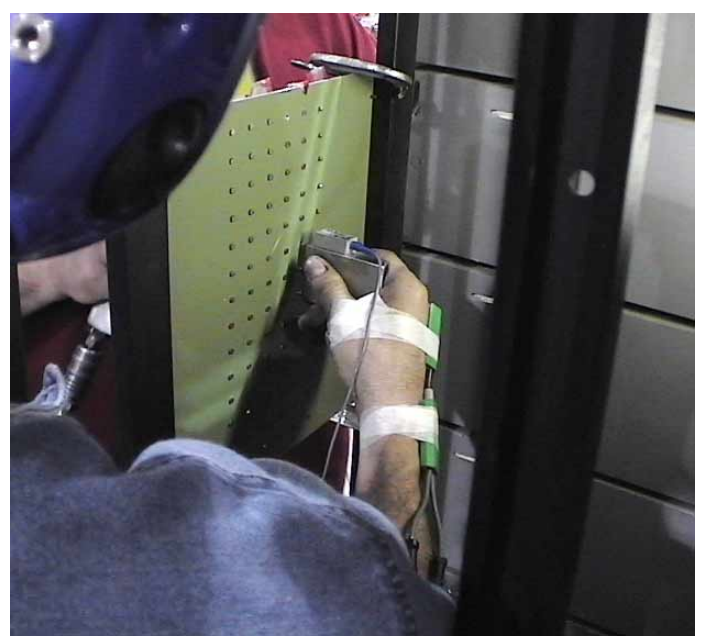

Figure 2. Accelerometer attached to the bucking bar during the experimental task. 


\section{Experimental Protocol}

The bipolar EMG electrodes were applied over the right flexor digitorum superficialis muscle group and the right extensor digitorum muscle group using standardized techniques (Zipp 1982), and a ground electrode was placed over the right lateral epicondyle. To obtain a reference value for muscle activity in order to compare the experimental trials, two five-second maximum voluntary contraction (MVC) power grip exertions were performed using a power grip dynamometer in the same posture as the experimental trials, followed by two five-second MVC static wrist extension exertion by the employee where the EMG muscle activity was captured. The accelerometer was attached to each bucking bar using double sided adhesive tape. Each subject would buck approximately 30 consecutive rivets (two vertical columns of rivets) with each of the bucking bars (Figure 2).

\section{Data Analysis}

The EMG signals from the sensors were already band-pass filtered between $30 \mathrm{~Hz}$ and 450 $\mathrm{Hz}$ due to the configuration of the EMG sensors. The EMG signals for the MVCs and experimental trials were full wave rectified and smoothed using a $60 \mathrm{msec}$ sliding moving average window. The experimental trial EMG analysis consisted of normalizing the wrist flexor and extensor muscle activity during the bucking bar exertions to the peak flexor and extensor muscle group activity elicited during the MVCs. Analysis on the normalized EMG signals included a determination of the mean normalized EMG signal across the different subjects as a function of each bucking bar.

The vibration data from the triaxial accelerometer was analyzed for the peak and mean resultant weighted acceleration for each bucking bar using window bins of 1024 data points and a Butterworth filter order of 2, with a low cutoff frequency of $1 \mathrm{~Hz}$ and high cutoff frequency of $2500 \mathrm{~Hz}$ using the Vibration Analysis Tool Set (VATS) software (NexGen Ergonomics). Based upon the magnitude of the vibration measured from each of the bucking bars, an estimate of the exposure period (years) until 10\% of the exposed population that have four hours of exposure per day develop the onset of vascular disorders (finger blanching) was determined according to ISO 5349.

\section{Statistical Analysis}

Descriptive statistics were derived for the mean and peak resultant weighted acceleration, mean hand/wrist flexor and extensor EMG and exposure period estimate. For each dependent variabie, a one-way repeated measures Analysis of Variance (ANOVA) was performed to determine if pere were differences in the dependent variables as a function of bucking bar type. Significant effects were investigated via Tukey pair-wise comparisons utilizing a family-wise $\alpha=0.05$.

\section{RESULTS}

The results for the mean normalized EMG, mean and peak resultant weighted acceleration and ISO 5349 estimate of exposure period as a function of bucking bar are shown in Table 1. The ANOVA indicated that the bucking bar had a significant affect on the vibration characteristics $(\mathrm{p}<0.0001)$. Tukey pairwise comparisons found that both tungsten bars resulted in significantly less mean resultant weighted acceleration ( $>90 \%$ tungsten, 3.4 $\mathrm{m} / \mathrm{s}^{2} ; 90 \%$ tungsten, $\left.3.6 \mathrm{~m} / \mathrm{s}^{2}\right)$ than either the cold rolled $\left(5.3 \mathrm{~m} / \mathrm{s}^{2}\right)$ or stainless steel $\left(5.6 \mathrm{~m} / \mathrm{s}^{2}\right)$ bar, but the two tungsten bars were not significantly different from each other (Figure 3). The same trend was found for the peak resultant weighted acceleration $(\mathrm{p}<0.0001)$, where both tungsten bars resulted in significantly less peak resultant weighted acceleration ( $>90 \%$ tungsten, $19.9 \mathrm{~m} / \mathrm{s}^{2}$; $90 \%$ tungsten, $20.3 \mathrm{~m} / \mathrm{s}^{2}$ ) than either the cold rolled bar $\left(30.9 \mathrm{~m} / \mathrm{s}^{2}\right)$ or the stainless steel bar $\left(31.7 \mathrm{~m} / \mathrm{s}^{2}\right)$. The estimated exposure period until $10 \%$ of the population exposed for 4 hours per day resulted in significant differences as a function of the bucking bar ( $\mathrm{p}<0.0001)$, with both tungsten bars $(>90 \%$, 9.0 years; $90 \%, 8.3$ years) resulting in a significantly longer period of time than either the cold rolled (5.5 years) or stainless steel (5.2 years) bars. 
The ANOVA on the muscle activity indicated that neither the mean hand/wrist flexor ( $\mathrm{p}$ $=0.3056)$ or extensor $(\mathrm{p}=0.7796)$ EMG muscle activity varied significantly as a function of bucking bar.

Table 1. Mean (SD) results for the dependent variables as a function of bucking bar type. Dependent variables with different letters (A and B) as a function of bucking bar material are significantly different.

\begin{tabular}{|c|c|c|c|c|}
\hline \multirow[b]{2}{*}{$\begin{array}{c}\text { Dependent } \\
\text { Variable }\end{array}$} & \multicolumn{4}{|c|}{ Bucking Bar } \\
\hline & $\begin{array}{c}>90 \% \\
\text { Tungste } \\
\text { n }\end{array}$ & $\begin{array}{c}90 \% \\
\text { Tungste } \\
\mathrm{n}\end{array}$ & $\begin{array}{c}\text { Cold } \\
\text { Rolled }\end{array}$ & $\begin{array}{c}\text { Stainless } \\
\text { Steel }\end{array}$ \\
\hline $\begin{array}{c}\text { Mean } \\
\text { Resultant } \\
\text { Weighted Acc } \\
\left(\mathrm{m} / \mathrm{s}^{2}\right)\end{array}$ & $\begin{array}{l}3.4^{\mathrm{A}} \\
(0.8)\end{array}$ & $\begin{array}{l}3.6^{\mathrm{A}} \\
(0.4)\end{array}$ & $\begin{array}{l}5.3^{\mathrm{B}} \\
(0.5)\end{array}$ & $\begin{array}{l}5.6^{\mathrm{B}} \\
(0.6)\end{array}$ \\
\hline $\begin{array}{c}\text { Peak } \\
\text { Resultant } \\
\text { Weighted Acc } \\
\left(\mathrm{m} / \mathrm{s}^{2}\right)\end{array}$ & $\begin{array}{l}19.9^{\mathrm{A}} \\
(2.7)\end{array}$ & $\begin{array}{l}20.3^{\mathrm{A}} \\
(2.9)\end{array}$ & $\begin{array}{l}30.9^{\mathrm{B}} \\
(2.6)\end{array}$ & $\begin{array}{l}31.7^{\mathrm{B}} \\
(3.0)\end{array}$ \\
\hline $\begin{array}{c}\text { Mean } \\
\text { Normalized } \\
\text { Flexor EMG } \\
(\% \text { MVC) } \\
\end{array}$ & $\begin{array}{l}0.31^{\mathrm{A}} \\
(0.13)\end{array}$ & $\begin{array}{l}0.36^{\mathrm{A}} \\
(0.14)\end{array}$ & $\begin{array}{l}0.36^{\mathrm{A}} \\
(0.15) \\
\end{array}$ & $\begin{array}{l}0.34^{\mathrm{A}} \\
(0.14)\end{array}$ \\
\hline $\begin{array}{c}\text { Mean } \\
\text { Normalized } \\
\text { Extensor } \\
\text { EMG } \\
(\% \mathrm{MVC}) \\
\end{array}$ & $\begin{array}{l}0.13^{\mathrm{A}} \\
(0.02)\end{array}$ & $\begin{array}{l}0.15^{\mathrm{A}} \\
(0.03)\end{array}$ & $\begin{array}{l}0.14^{\mathrm{A}} \\
(0.02)\end{array}$ & $\begin{array}{l}0.14^{\mathrm{A}} \\
(0.01)\end{array}$ \\
\hline $\begin{array}{c}\text { Exposure } \\
\text { Period } \\
\text { (years) }\end{array}$ & $\begin{array}{l}9.0^{\mathrm{A}} \\
(2.0)\end{array}$ & $\begin{array}{l}8.3^{\mathrm{A}} \\
(1.0)\end{array}$ & $\begin{array}{l}5.5^{\mathrm{B}} \\
(0.5)\end{array}$ & $\begin{array}{l}5.2^{\mathrm{B}} \\
(0.6)\end{array}$ \\
\hline
\end{tabular}

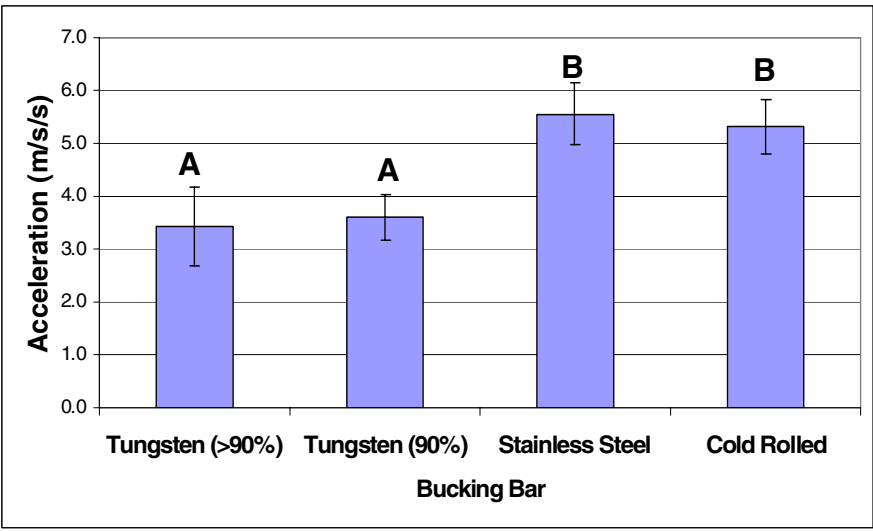

Figure 3. Mean resultant weighted acceleration as a function of bucking bar (error bars represent +/- one standard deviation). Bars with same letters are not significantly different from each other.

\section{DISCUSSION}

Vibration exposure from riveting tasks during the assembly of aircraft arises from several sources, including rivet guns, power drills, and using bucking bars. Although vibration dampened rivet guns are currently available, their use among experienced riveters has been reported to have a negative affect on quality of the rivets due to overdriving rivets because of the loss of the "feel" when the rivet is set, resulting in rework (Melhorn 1996). Spring dampened bucking bars were also availabie to the employees at the aircraft manulacturing site, however, subjective reports fiom experienced employees indicated that these spring dampened bucking bars did not allow for the "feel" of when the rivet was completely set. Thus, the experienced employees preferred the metal bucking bars.

Efforts to reduce the risk of MSD from vibration exposure can be achieved by eliminating the vibration exposure, reducing the duration of vibration exposure, or reducing the magnitude of the vibration acceleration. The current study investigated the potential to reduce the magnitude of the vibration acceleration by using a bucking bar made from alternate materials. Although subjective reports from employees indicated that the vibration was reduced by using the heavier tungsten bars compared to using the traditional steel bucking bars, the effect that the larger mass of the tungsten bar might have on the grip force was unknown. Thus, the safety personnel did not want to utilize tungsten bucking bars if their use resulted in increased grip force during the riveting tasks as compared to the steel bucking bars that were currently in use.

The magnitude of the acceleration measured on the steel bucking bars in this study (5.3 to 5.6 $\mathrm{m} / \mathrm{s}^{2}$ ) was of the same magnitude found at the lower end of the range of mean frequency weighted accelerations (5.5 to $12.3 \mathrm{~m} / \mathrm{s}^{2}$ ) measured on bucking bars by Burdorf and Monster (1991). The population studied by Burdorf and Monster (1991) showed significant associations between duration of riveting (in years) and complaints of pain or stiffness of the wrist, as well as symptoms of white finger. Thus, there is historical support for efforts 
to reduce the magnitude and duration of exposure to vibration during riveting tasks in aircraft manufacturing.

The results of this study indicate that the bucking bars made of tungsten resulted in significantly less vibration measured at the bucking bar when compared to the other two bucking bar materials (cold rolled and stainless steel). The $>90 \%$ tungsten bar resulted in a $34 \%$ decrease in the resultant weighted acceleration when compared to using the cold rolled bar, and a $37.5 \%$ decrease when compared to using the stainless steel bar. Additionally, the $>90 \%$ tungsten bar resulted in $2.8 \%$ less vibration transmission than the $90 \%$ tungsten bar, although this difference was not statistically significant. The magnitude of the weighted resultant acceleration indicates how fast the bucking bar is "bouncing" or moving as the energy is transferred from the rivet gun through the rivet to the bucking bar. Thus, a bucking bar that is accelerating less would be expected to resilt in lower grip force to control the bucking tor. However, results from the EMG indicated that there was no significant difference in the mean wrist flexor or extensor muscle activity as a function of bucking bar. Although there was not a significant decrease in the mean EMG muscle activity, there also was not a significant increase either. Thus, when using bucking bars of the same size, the heavier tungsten bars were superior to the traditional steel bucking bars in terms of dampening vibration transmission without the added cost of increased muscle force to control the bars during riveting. This may also result in a positive health effect as the tungsten bucking bars resulted in an increase in the estimated duration for $10 \%$ of the exposed population at the measured acceleration levels to show symptoms of finger blanching (ISO 5349) of at least $49 \%$ and $64 \%$ when compared to the cold rolled and stainless steel bars, respectively.

Several limitations exist regarding the extrapolation of these findings. First, it is known that grip force increases when gripping a vibrating handle as compared to gripping a static handle (Radwin et al. 1987), and that electrical activity of the finger flexor muscles increases with grip force, where the increase is larger at higher acceleration levels (Gurram et al. 1995). Although the normalized EMG for the flexor and extensor muscles showed no significant differences as a function of bucking bar, the true internal effect on muscle force cannot be ascertained from this study. Second, only one rivet size, one skin material, one bucking bar size, and one rivet gun were investigated. Other sizes of rivets, rivet guns and skin material may result in different levels of vibration.

\section{CONCLUSIONS}

While controlling for rivet size, air hammer, skin material, and bucking bar shape, the tungsten backing bars resulted in a decrease transmission of vibration, with no difference observed for grip muscle activity. Thus, when access (i.e., clearance for the bucking bar and hand) dictates that the size of the bucking bar be used that was investigated in this study, it appears that the use of a bucking bar made of tungsten, which will have a larger mass than the traditionally used steel bars, may be useful in reducing vibration transmission and positively affecting the health and safety of the employees.

\section{REFERENCES}

Burdorf A and Monster A. Exposure to vibration and self-reported health complaints of riveters in the aircraft industry. Ann Occup Hyg 1991; 35(3):287-298.

Dandanell R and Engstrom K. Vibration from riveting tools in the frequency range $6 \mathrm{~Hz}-10 \mathrm{~Hz}$ and Raynaud's phenomenon. Scand J Work Environ Health 1986; 12:338-342.

Engstrom K and Dandanell R. Exposure conditions and Raynaud's phenomenon among riveters in the aircraft industry. Scand J Work Environ Health 1986; 12:293-295.

Gurram R, Rakheja S and Gouw GJ. A study of hand grip pressure distribution and EMG of finger flexor muscle under dynamic loads. Ergonomics 1995; 38:684-699.

International Organization for Standardization (ISO). Guidelines for the measurement and assessment of human exposure to vibration transmitted to the hand. Geneva 1984, ISO 5349.

Melhorn JM. A prospective study for upper-extremity cumulative trauma disorders of workers in aircraft manufacturing. J Occup Environ Med 1996; 38(12):1264-1271.

Radwin RG, Armstrong TJ and Chaffin DB. Power hand tool vibration effects on grip exertions. Ergonomics 1987; 30:833-855.

Zipp P. Recommendations for the standardization of lead positions in surface electromyography. Eur J Appl Physiol 1982; 50:41-54. 